\title{
Effects of Electrical Pulse and 6-DMAP on Cleavage of Golden Hamster Oocytes-Morphological and Phisiological Observations
}

\author{
Lingyan Wang *, Han Jiang and Ziyi Li * \\ Jilin Province Key Laboratory of Animal Embryo Engineering, College of Animal Science and \\ Veterinary Medicine, Jilin University, Changchun 130062, China; jiangha@ohsu.edu \\ * Correspondence: wangli@ohsu.edu (L.W.); ziyi_li86@163.com (Z.L.); Tel.: +1-503-494-4568 (L.W.); \\ +86-431-8783-6187 (Z.L.)
}

Academic Editor: Giuseppe Musumeci

Received: 28 April 2016; Accepted: 25 May 2016; Published: 30 May 2016

\begin{abstract}
The golden hamster is a well-established model system for studies of morphology, reproductive physiology, oncology, genetics and virology. The aim of this study was to establish experimental protocols necessary for cloning the golden hamster; we examined and optimized conditions for parthenogenesis and cleavage of its oocytes. We tested oocytes of different ages, including $15 \mathrm{~h}$ after Human chorionic gonadotropin (hCG), with two treatments: (1) an electrical pulse ranging from 10 to $600 \mathrm{~V} / \mathrm{mm}$ and (2) incubation for 2 to $6 \mathrm{~h}$ in $2 \mathrm{mM}$ 6-dimethylaminopurine (6-DMAP). These two conditions were tested both separately and in combination. We found that (i) in oocytes of different ages, cleavage exhibits a strength-dependent increase; (ii) 6-DMAP stimulates oocyte cleavage, but the cleavage rates are significantly low; and (iii) a combined treatment is more effective than a treatment with 6-DMAP alone, and is comparable to those achieved with high pulse stimuli. These results elucidate certain parameters important for the cloning of the golden hamster species.
\end{abstract}

Keywords: electrical pulse; 6-DMAP; cleavage; oocytes; golden hamster

\section{Introduction}

The golden hamster is an excellent model organism for many research fields. It represents an attractive species for studies ranging from morphology, reproductive physiology, oncology, genetics and virology. In order to establish experimental protocols necessary for cloning golden hamsters, several studies related to hamster oocyte enucleation have been reported [1,2]. In this study, we optimized the conditions for parthenogenesis and cleavage of golden hamster oocytes. Previous studies have reported that parthenogenetic activation of oocytes from several species may be induced by chemical reagents, including calcium ionophore [3], strontium $\left(\mathrm{Sr}^{2+}\right)$ [4], ethanol [5], cycloheximide [6], 6-dimethylaminopurine (6-DMAP) [7], as well as by electrical stimulation [8]. Despite these findings, the activation and cleavage induction of oocytes remains one of the least efficient steps in the nuclear transplantation process.

Hamster oocytes can be activated spontaneously when cultured in vitro [9,10]. Gwatkin [11] found that electrical stimulation was highly effective in activation of hamster oocytes. However, activated oocytes are not guaranteed to undergo cleavage. In order to elucidate the parameters important for golden hamster cloning, we studied in detail the effect of different intensities of electrical pulse stimulations on the cleavage of oocytes. 6-DMAP are known to accelerate and enhance the formation of pronuclei [12]. Most mammalian oocytes, including those of ferrets [13], pig [14] and mice [5], can be activated, and cleavage may be induced by electrical stimuli combined with 6-DMAP treatments. 
However, the efficiency of 6-DMAP activation remains unknown in hamster oocytes. We describe the cleavage-inducing effects of 6-DMAP and electrical stimulation, both alone and in combination.

\section{Materials and Methods}

\subsection{Chemicals and Animals}

All chemicals were purchased from Sigma Chemical Co. (St. Louis, MO, USA) and Invitrogen Co. (Grand Island, NY, USA) unless otherwise noted. The golden hamster specimens (female, 6 weeks of age) were purchased from Changchun Hi-Tech Laboratory Animal Research Center (Changchun, China) and housed at a density of three animals per cage under controlled light cycle conditions (14 L:10 D). Animal treatment complied with a protocol approved by the Jilin University Institutional Animal Care and Use Committee.

\subsection{Collection of Oocytes}

The hamsters were superovulated with pregnant mare serum gonadotrpin (PMSG, 30 IU, ip) followed by human chorion gonadotropin (hCG, $30 \mathrm{IU}$, ip) at intervals of $72 \mathrm{~h}$. Both PMSG and hCG were obtained from Ningbo Hormone Product Co., Ltd., Ningbo, China. The superovulated hamsters were sacrificed at different times after hCG injection $(13.5,15,17,19 \mathrm{~h})$, and the oviductal ampullae were broken to release the cumulus-oocyte complexes (COCs). Cumulus cells were subsequently removed from the COCs by pipetting with a thin pipette in M2 [15] containing $0.1 \%$ hyaluronidase (Sigma, H4272). The oocytes were activated immediately after washing, rinsed, and then kept at $37.5^{\circ} \mathrm{C}$ under $5 \% \mathrm{CO}_{2}$.

\subsection{Culture Media}

The medium used for collection and culturing was M199TE [16], which contained TCM199 (with Earle salt, $26 \mathrm{mM}$ sodium bicarbonate, and $25 \mathrm{mM}$ Hepes; Gibco BRL, Grand Island, NY, USA) supplemented with 5\% heat-inactivated fetal bovine serum (Gibco BRL), $5 \mathrm{mM}$ taurine and $25 \mu \mathrm{M}$ EDTA.

\subsection{Activation and Cleavage}

Electrical stimulation: Hamster oocytes collected at different times post-hCG injection were transferred to activation medium (0.3 M mannitol, $0.1 \mathrm{mM} \mathrm{MgCl} 2,0.1 \mathrm{mM} \mathrm{CaCl}_{2}$, and $0.01 \%(w / v)$ BSA) and placed between parallel electrodes (spacing, $1 \mathrm{~mm}$ ) in the chamber of a BTX Electro-cell Manipulator 2001 (BTX, San Diego, CA, USA). The duration of the electrical stimulation was $10 \mu \mathrm{s}$. To test the tolerance and cleavage of the oocytes, we first treated $15 \mathrm{~h}$ post-hCG oocytes with different pulse intensities $(10,30,50,100,200,300,400,500,550$ and $600 \mathrm{~V})$. We then tested the cleavage rate of oocytes of different ages $(13.5,15,17,19$ h post-hCG) under different electrical intensities (50, 100, 300, $500 \mathrm{~V})$. The oocytes of control groups were incubated in activation medium for $2 \mathrm{~min}$ before being transferred to the culture medium.

Chemical stimulation: We first tested $15 \mathrm{~h}$ post-hCG oocytes for incubation at different durations $(0.5,1,2,4,6$ and $8 \mathrm{~h}$ ) in M199TE containing with $2 \mathrm{mM}$ of 6-DMAP (Sigma D-2629). We then tested the cleavage rate of different ages of oocytes $(13.5,15,17,19 \mathrm{~h}$ post-hCG) over a range of 6-DMAP treatment durations $(2,4$ and $6 \mathrm{~h})$. Effects of 6-DMAP on oocyte activation were compared to the control groups incubated in M199TE without chemical supplement.

Combined electrical and chemical stimulation: In order to maximize the cleavage rate, oocytes were subjected to a combination of electrical and chemical activation stimuli. Oocytes were treated with electrical stimulation $(300 \mathrm{~V} / \mathrm{mm}, 10 \mu \mathrm{s})$ followed by a treatment with 6-DMAP ( 2 or $4 \mathrm{~h}$ ). 


\subsection{Assessment of Oocyte Cleavage}

After culturing overnight following treatment, the oocytes were examined under a microscope to assess activation and cleavage. Only oocytes with two nucleated cells were considered cleaved.

\subsection{Staining and Observation of the Oocyte Cleavage Process}

Oocytes were cultured in M199TE after being treated with $2 \mathrm{mM}$ 6-DMAP for $2 \mathrm{~h}$. Every $4 \mathrm{~h}$ the oocytes were collected and fixed in PBS with $4 \%$ paraformaldehyde (pH 7.4) for 40 min at room temperature (RT). Fixed samples were permeabilized by transferring into PBS supplemented with $0.1 \%(w / v)$ Triton-X100 and $0.3 \%$ BSA for 30 to $40 \mathrm{~min}$ at RT. After washing twice in PBS with $0.01 \%$ Triton-X100, samples were incubated in block solution (PBS containing $1 \% \mathrm{BSA}$ ) for $1 \mathrm{~h}$ at RT. The microtubules were localized by incubation for $1 \mathrm{~h}$ at RT with a fluorescein isothiocyanate-labeled mouse monoclonal antibody against $\alpha$-tubulin (Sigma, F-2168) diluted 1:100 in blocking solution. The nuclear status of the samples was evaluated by staining with $10 \mu \mathrm{g} / \mathrm{mL}$ propidium iodide (PI) in PBS for $10 \mathrm{~min}$. After thorough washing, samples were mounted on slides with antifluorescence-fade medium (1,4-diazobicyclo-[2,2,2]-octane, DABCO, Sigma, D-2522). Samples were subsequently observed under a confocal laser scanning microscope (Olympus, Tokyo, Japan).

\subsection{Data Analysis}

Three replicate trials were conducted for each treatment. The mean percentage $( \pm S E M)$ was calculated for each experimental group. Data were analyzed by one-way analysis of variance (ANOVA), using SPSS (Statistics Production for Service Solution, Version 12.0, Chicago, IL, USA) software after being transformed via LSD. The difference was considered significant when $p<0.05$.

\section{Results}

\subsection{Cleavage of Oocytes at $15 \mathrm{~h}$ Post-hCG after Electrical Stimulus}

Oocytes at $15 \mathrm{~h}$ post-hCG were stimulated for $10 \mu$ s with different electrical pulses ranging from 10 to $600 \mathrm{~V} / \mathrm{mm}$. The proportion of cleaved oocytes was observed after an overnight culture. A $10 \mathrm{~V} / \mathrm{mm}$ pulse was insufficient to induce cleavage, but increasing pulse intensity correlated with increasing proportions of cleaved oocytes. When subjected to a pulse of $300 \mathrm{~V} / \mathrm{mm}, 81.00 \%$ of oocytes induced cleavage, and after a pulse of $500 \mathrm{~V} / \mathrm{mm}$, all of oocytes developed to the 2-cell stage. The cleavage rate was low and relatively consistent after 300,400 and $500 \mathrm{~V} / \mathrm{mm}$ stimulation. With a pulse of $550 \mathrm{~V} / \mathrm{mm}$ and above, oocytes began to die immediately following treatment (see Table 1).

Table 1. Effect of different electrical pulses on cleavage of $15 \mathrm{~h}$ post-hCG oocytes.

\begin{tabular}{cccc}
\hline $\begin{array}{c}\text { Electrical Pulse } \\
\text { (V/mm) }\end{array}$ & $\begin{array}{c}\text { No. of Oocytes } \\
\text { Examined }\end{array}$ & $\begin{array}{c}\text { No. of Oocytes } \\
\text { Cleaved }\end{array}$ & $\begin{array}{c}\text { \% of Cleavage } \\
\text { (mean } \pm \text { SE) }\end{array}$ \\
\hline 10 & 32 & 0 & $0.00 \pm 0.00^{\mathrm{a}}$ \\
30 & 38 & 12 & $31.00 \pm 7.57^{\mathrm{b}}$ \\
50 & 27 & 11 & $41.33 \pm 8.25^{\mathrm{b}}$ \\
100 & 33 & 24 & $75.00 \pm 7.00^{\mathrm{c}}$ \\
200 & 30 & 20 & $64.00 \pm 14.18^{\mathrm{c}}$ \\
300 & 60 & 48 & $81.00 \pm 9.71^{\mathrm{c}} \mathrm{d}$ \\
400 & 28 & 27 & $96.33 \pm 3.67^{\mathrm{d}}$ \\
500 & 45 & 45 & $100.00 \pm 0.00^{\mathrm{d}}$ \\
550 & 27 & 20 & $74.33 \pm 5.46^{\mathrm{c}}$ \\
600 & 24 & $0^{*}$ & $0.00 \pm 0.00^{\mathrm{a}}$
\end{tabular}

* Oocytes died after electrical stimulus; ${ }^{\text {a-d }}$ Values with different superscripts within the same column are significantly different $(p<0.05)$. 


\subsection{Cleavage of Oocytes at 13.5-19 h Post-hCG after Electrical Stimulus}

Oocytes at 13.5, 15, 17 and $19 \mathrm{~h}$ post-hCG were electrically stimulated with pulses of 50, 100, 300 and $500 \mathrm{~V} / \mathrm{mm}$. The cleavage rates of differentially-aged oocytes increased with pulse intensity. Oocytes at $13.5 \mathrm{~h}$ post-hCG could not withstand the $500 \mathrm{~V} / \mathrm{mm}$ pulse, and all of them died immediately following stimulation. The pulse of $300 \mathrm{~V} / \mathrm{mm}$ could induce cleavage in $13.5,17$ or $19 \mathrm{~h}$ post-hCG injection oocytes. Comparing results from every pulse group, we found that oocytes at $15 \mathrm{~h}$ post-hCG showed the highest rate of cleavage, and a pulse of $500 \mathrm{~V} / \mathrm{mm}$ could fully activate oocytes $15 \mathrm{~h}$ post-hCG, with a cleavage rate up to $100 \%$ (see Table 2).

Table 2. Effect of different electrical pulses on cleavage of different ages of oocytes.

\begin{tabular}{|c|c|c|c|c|}
\hline $\begin{array}{l}\text { Electrical Pulse } \\
\text { (V/mm) }\end{array}$ & Hours Post-hCG & $\begin{array}{l}\text { No. of Oocytes } \\
\text { Examined }\end{array}$ & $\begin{array}{l}\text { No. of Oocytes } \\
\text { Cleaved }\end{array}$ & $\begin{array}{l}\% \text { of Cleavage } \\
(\text { mean } \pm \text { SE) }\end{array}$ \\
\hline \multirow{4}{*}{50} & 13.5 & 36 & 6 & $12.67 \pm 12.67^{a, b}$ \\
\hline & 15 & 27 & 11 & $41.33 \pm 8.25^{\mathrm{a}}$ \\
\hline & 17 & 27 & 4 & $14.00 \pm 7.37^{\mathrm{a}, \mathrm{b}}$ \\
\hline & 19 & 21 & 2 & $7.33 \pm 7.33^{b}$ \\
\hline \multirow{4}{*}{100} & 13.5 & 33 & 3 & $7.33 \pm 3.84^{\mathrm{a}, \mathrm{c}}$ \\
\hline & 15 & 33 & 24 & $75.00 \pm 7.00^{b}$ \\
\hline & 17 & 29 & 3 & $60.33 \pm 11.69^{b}$ \\
\hline & 19 & 29 & 18 & $13.67 \pm 9.94^{\mathrm{c}}$ \\
\hline \multirow{4}{*}{300} & 13.5 & 31 & 7 & $21.67 \pm 11.28^{a}$ \\
\hline & 15 & 60 & 48 & $81.00 \pm 9.71^{b}$ \\
\hline & 17 & 28 & 16 & $63.33 \pm 9.28^{b, c}$ \\
\hline & 19 & 20 & 8 & $39.00 \pm 3.22^{a, c}$ \\
\hline \multirow{4}{*}{500} & 13.5 & 33 & $0 *$ & $0.00 \pm 0.00^{a, *}$ \\
\hline & 15 & 45 & 45 & $100.00 \pm 0.00^{b}$ \\
\hline & 17 & 22 & 9 & $41.00 \pm 14.29^{c}$ \\
\hline & 19 & 38 & 14 & $31.67 \pm 9.28^{c}$ \\
\hline
\end{tabular}

* Oocytes died after electrical stimulus; ${ }^{\text {a-c }}$ Values with different superscripts within one column of the same electrical pulse are significantly different $(p<0.05)$.

\subsection{Cleavage of Oocytes at $15 \mathrm{~h}$ Post-hCG after 6-Dimethylaminopurine (6-DMAP) Treatment}

Oocytes at $15 \mathrm{~h}$ post-hCG were treated with $2 \mathrm{mM}$ 6-DMAP for 0.5, 1, 2, 4, 6 or $8 \mathrm{~h}$ in M199TE. Oocytes were then transferred to M199TE and cultured overnight. Treatment for $0.5 \mathrm{~h}$ with 6-DMAP induced very few oocyte cleavages. Treatment with 6-DMAP for $4 \mathrm{~h}$ induced the highest rate of oocyte cleavages, significantly higher than the rate induced by the $0.5 \mathrm{~h}$ 6-DMAP treatment group. However, treatments lasting for more than $4 \mathrm{~h}$ saw a decreasing rate of cleavage, diminishing to $24.23 \%$ when oocytes were treated for $8 \mathrm{~h}$ (see Table 3 ).

Table 3. Cleavage of oocytes ( $15 \mathrm{~h}$ post $\mathrm{hCG}$ ) after different duration of 6-dimethylaminopurine (6-DMAP) treatment.

\begin{tabular}{cccc}
\hline $\begin{array}{c}\text { Duration of } \\
\text { 6-DMAP (h) }\end{array}$ & $\begin{array}{c}\text { No. of Oocytes } \\
\text { Examined }\end{array}$ & $\begin{array}{c}\text { No. of } \\
\text { Cleavage }\end{array}$ & $\begin{array}{c}\text { \% of Cleavage } \\
\text { (mean } \pm \text { SE) }\end{array}$ \\
\hline 0.5 & 39 & 8 & $19.44 \pm 4.24^{\mathrm{a}}$ \\
1 & 40 & 12 & $34.33 \pm 11.37^{\mathrm{a}, \mathrm{b}}$ \\
2 & 51 & 23 & $45.21 \pm 10.65^{\mathrm{a}, \mathrm{b}}$ \\
4 & 50 & 23 & $46.82 \pm 5.40^{\mathrm{b}}$ \\
6 & 50 & 18 & $35.89 \pm 13.33^{\mathrm{a}, \mathrm{b}}$ \\
8 & 39 & 9 & $24.23 \pm 2.25^{\mathrm{a}, \mathrm{b}}$ \\
\hline
\end{tabular}

${ }^{\mathrm{a}, \mathrm{b}}$ Values with different superscripts are significantly different $(p<0.05)$. 


\subsection{Cleavage of Oocytes at 13.5-19 h Post-hCG after 6-DMAP Treatment}

Oocytes of different ages were treated with $2 \mathrm{mM}$ of 6-DMAP for 2, 4 and $6 \mathrm{~h}$. As Table 4 shows, oocytes at 13.5 and $15 \mathrm{~h}$ post-hCG had a higher cleavage rate no matter how long the treatment. When they became older, very few of oocytes at 17 and $19 \mathrm{~h}$ post-hCG could be cleaved when the 6-DMAP duration was longer than $2 \mathrm{~h}$ (see Table 4).

Table 4. Cleavage of oocytes in different age after different duration of 6-DMAP treatment.

\begin{tabular}{ccccc}
\hline Hours Post-hCG & $\begin{array}{c}\text { Duration of } \\
\text { 6-DMAP (h) }\end{array}$ & $\begin{array}{c}\text { No. of Oocytes } \\
\text { Examined }\end{array}$ & $\begin{array}{c}\text { No. of Oocytes } \\
\text { Cleaved }\end{array}$ & $\begin{array}{c}\text { \% of Cleavage } \\
\text { (mean } \pm \text { SE) }\end{array}$ \\
\hline \multirow{3}{*}{13.5} & 2 & 43 & 18 & $47.12 \pm 15.44^{\mathrm{a}}$ \\
& 4 & 43 & 14 & $39.23 \pm 17.12^{\mathrm{a}}$ \\
& 6 & 41 & 19 & $46.21 \pm 9.04^{\mathrm{a}}$ \\
15 & 2 & 50 & 23 & $45.21 \pm 10.65^{\mathrm{a}}$ \\
& 4 & 51 & 23 & $46.82 \pm 5.40^{\mathrm{a}}$ \\
& 6 & 51 & 18 & $35.89 \pm 13.33^{\mathrm{a}}$ \\
& 2 & 32 & 5 & $13.89 \pm 7.35^{\mathrm{a}}$ \\
& 4 & 32 & 1 & $4.17 \pm 4.17^{\mathrm{a}}$ \\
& 6 & 34 & 0 & $0.00 \pm 0.00^{\mathrm{a}}$ \\
& 2 & 34 & 6 & $16.27 \pm 12.87^{\mathrm{a}}$ \\
& 4 & 34 & 0 & $0.00 \pm 0.00^{\mathrm{a}}$ \\
\hline
\end{tabular}

a Values with the same superscripts within one column of oocytes at same age are not significantly different $(p>0.05)$.

\subsection{Cleavage of Oocytes after Combined Treatment of Electrical Pulse and 6-DMAP}

When oocytes were treated with a $300 \mathrm{~V} / \mathrm{mm} 10 \mu$ s electrical pulse followed by 2 or $4 \mathrm{~h}$ of 6-DMAP incubation, more than $90 \%$ of the samples achieved cleavage. This rate was somewhat higher than the most effective low electrical stimulus $(300 \mathrm{~V} / \mathrm{mm})$ alone, and was significantly higher than the most effective 6-DMAP stimulus alone (see Table 5).

Table 5. Cleavage of oocytes after $10 \mu \mathrm{s}, 300 \mathrm{~V} / \mathrm{mm}$ electrical stimulus and different duration of 6-DMAP treatment.

\begin{tabular}{ccccc}
\hline $\begin{array}{c}\text { Duration of } \\
\text { 6-DMAP (h) }\end{array}$ & $\begin{array}{c}\text { Electrical } \\
\text { Stimulus }\end{array}$ & $\begin{array}{c}\text { No. of Oocytes } \\
\text { Examined }\end{array}$ & $\begin{array}{c}\text { No. of Oocytes } \\
\text { Cleaved }\end{array}$ & $\begin{array}{c}\text { \% of Cleavage } \\
\text { (mean } \pm \text { SE) }\end{array}$ \\
\hline 0 & + & 60 & 48 & $81.00 \pm 9.71^{\mathrm{a}}$ \\
2 & + & 54 & 52 & $96.49 \pm 3.51^{\mathrm{a}}$ \\
2 & - & 51 & 23 & $45.21 \pm 10.65^{\mathrm{b}}$ \\
4 & + & 60 & 54 & $90.44 \pm 1.55^{\mathrm{a}}$ \\
4 & - & 50 & 23 & $46.82 \pm 5.40^{\mathrm{b}}$ \\
\hline
\end{tabular}

$\mathrm{a}, \mathrm{b} \overline{\text { Values with different superscripts are significantly different }(p<0.05) .+ \text {, oocytes were treated with } 10} \mu \mathrm{s}$, $300 \mathrm{~V} / \mathrm{mm}$ electrical stimulus; -, oocytes were not treated with $10 \mu \mathrm{s}, 300 \mathrm{~V} / \mathrm{mm}$ electrical stimulus.

\subsection{Process of Hamster Oocyte Cleavage}

Oocyte spindles and chromosomes were stained at different time points following treatments. Cleaved oocytes were stained at the second meiotic metaphase (see Figure 1A; Figure 1E was unstained). After treatment, oocytes initiated the process of cleavage. Initially, the spindle disappeared and the chromosomes agglutinated into the nucleus (see Figure 1B). Subsequently, the nucleus cleaved into two nuclei and the oocyte cleaved into two cell blastomeres (Figure $1 \mathrm{C}, \mathrm{D}, \mathrm{F}$ ). 

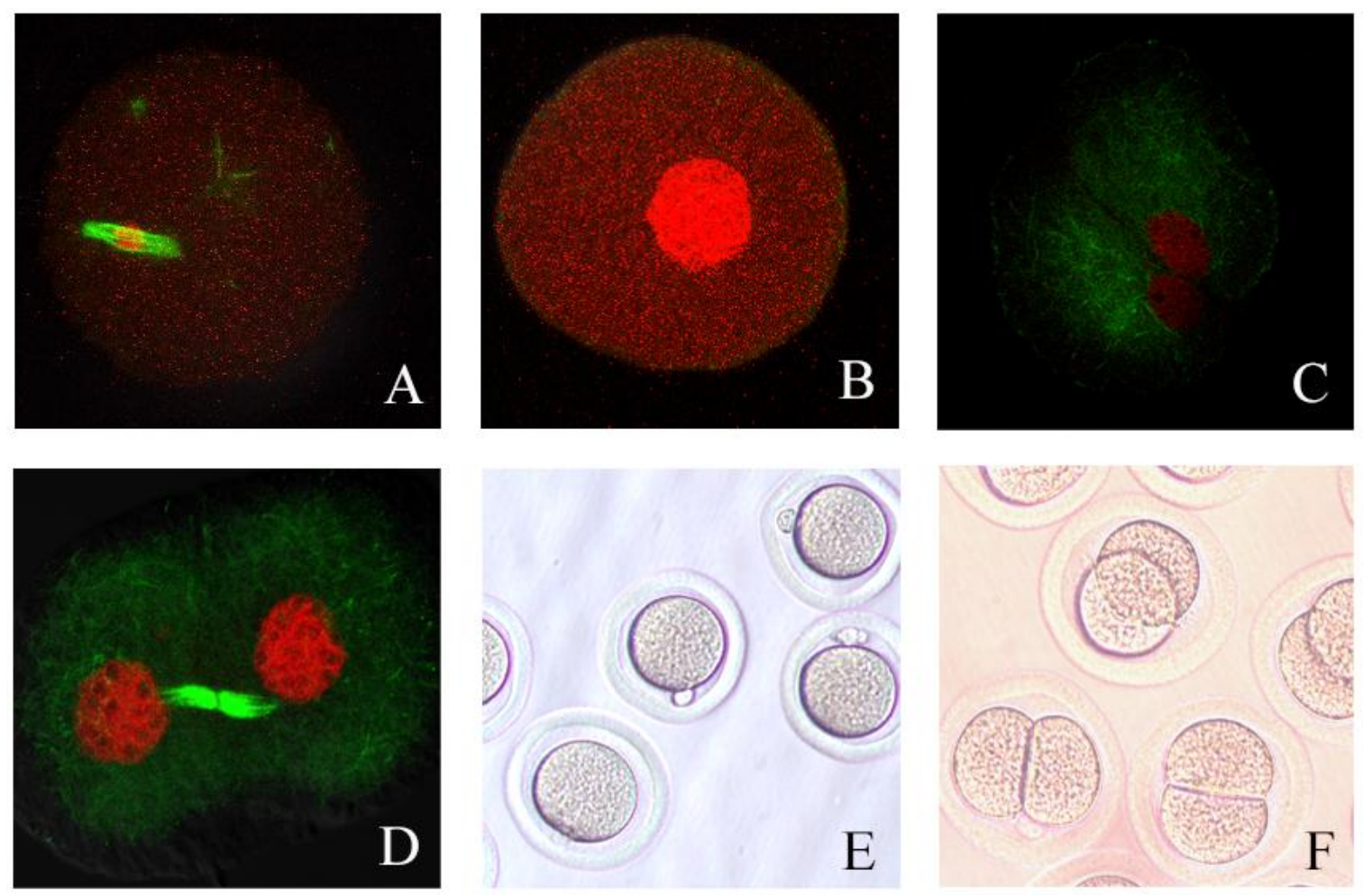

Figure 1. Confocal micrographs of oocyte activation process. (A) Matured oocyte used for activation, showing the morphology of the spindle (green) and chromosomes (red); (B) spindle disappeared and chromosomes condensed to one nuclear package; (C) nucleus divided into two pronuclei, then immediately (D) cleaved into two approximately equal-size blastomeres. Magnification: 600×; green: spindle; red: chromosomes; $(\mathbf{E}, \mathbf{F})$ normal oocytes and cleaved blastomeres observed under phase-contrast microscope, Magnification: $200 \times$

\section{Discussion}

Activation of oocytes is essential for successful embryo production following nuclear transfer (NT) or intracytoplasmic sperm injection (ICSI). Electric pulses have been shown to permeabilize the cell membrane, inducing an influx of extracellular calcium into the cytoplasm [17] and a rise in calcium oscillations within the oocyte [18]. Therefore, it is not surprising that electric stimulation is one of most effective methods of activating mammalian oocytes. Treatment with 6-DMAP has been used in activating oocytes of many species, including mice [5], pigs [19], cattle [20], dromedary camels [21], as well as others. But to our knowledge, this is the first report addressing the effect of 6-DMAP treatment on hamster oocyte cleavage.

Gwatkin [11] repored that electrical stimulation could activate hamster oocytes. Ogura [22] found that hamster spermatid-oocyte fusion could be induced through direct current pulse ( $300 \mathrm{~V} / \mathrm{mm}, 10 \mu \mathrm{s})$. We therefore used a pulse of $300 \mathrm{~V} / \mathrm{mm}, 10 \mu \mathrm{s}$ and $15 \mathrm{~h}$-post-hCG oocytes as a standard, and modulated both voltage and oocyte age to optimize this treatment. Following electrical stimulation, the cleavage of ferret oocytes [13] showed an age-dependent increase in the occurrence of cleavage and development to the morula and blastocyst stages. Bovine oocytes activate in response to ionophore A23187 treatment, electrical pulse, or ethanol treatment in an age-dependent manner [23], and electrically stimulated porcine oocytes show a similar trend [24]. We found that the hamster oocyte cleavage rate also increased with age, with a greater proportion of $15 \mathrm{~h}$ post-hCG oocytes cleaving than $13.5 \mathrm{~h}$ post-hCG oocytes. However, cleavage rates decreased with age in oocytes older than $15 \mathrm{~h}$ (17 and $19 \mathrm{~h}$ post-hCG). According to Yanagimachi and Chang [25], golden hamster oocytes begin spontaneous activation in vivo between 12 and $18 \mathrm{~h}$ post-ovulation. Although older oocytes are easily activated, spontaneous activation could induce cleavage. Our results showed that cleavage rates of oocytes at different 
ages increased with voltage. Oocytes of different ages also showed different tolerances to electrical treatments. Oocytes at $13.5 \mathrm{~h}$ post-hCG could not withstand treatments of $500 \mathrm{~V} / \mathrm{mm}$, and many 15 h-post-hCG oocytes could not withstand $550 \mathrm{~V} / \mathrm{mm}$. Older oocytes showed greater tolerance, and the electrical stimulus condition chosen to treat hamster oocytes should take into account the age of the oocytes.

6-DMAP is an inhibitor of protein kinases, and is widely used for activation of mammalian oocytes due to its ability to enhance activation stimuli and accelerate the formation of pronuclei [26]. Studies in pig oocytes showed that 6-DMAP treatments may impair parthenogenetic development of the activated oocytes. Grupen [16] showed that treatment with 2 or $5 \mathrm{mM}$ 6-DMAP for $3 \mathrm{~h}$ after electrical pulse increased the incidence of blastocyst formation, whereas treatment with 2 or $5 \mathrm{mM}$ 6-DMAP for $5 \mathrm{~h}$ did not. In our study, hamster oocytes collected at $15 \mathrm{~h}$ post-hCG injection were treated directly with $2 \mathrm{mM}$ 6-DMAP for different durations $(0.5-8 \mathrm{~h})$. Oocytes treated with 6-DMAP for 2 and $4 \mathrm{~h}$ had higher rates of cleavage $(45.21 \%$ and $46.82 \%)$ than those treated with 6-DMAP for $0.5,1,6$ and $8 \mathrm{~h}$. This indicated that sufficient 6-DMAP treatment duration was necessary to induce oocyte cleavage, but excessively long treatments with 6-DMAP induced detrimental effects on the development of parthenogenetic hamster embryos. Numerous abnormalities were observed when oocytes were activated with 6-DMAP for longer durations, and these abnormalities included inhibited spindle rotation and impaired exchange of protamines into histones [27]. In golden hamster 17 and $19 \mathrm{~h}$ post-hCG oocytes, treatment with 6-DMAP for $2 \mathrm{~h}$ induced only $13.89 \%$ and $16.27 \%$ oocyte cleavage, respectively. When treated for $6 \mathrm{~h}$, however, none of the oocytes were induced to cleave. We conclude that the rate of cleavage after 6-DMAP treatment is age-dependent, with younger oocytes ( 13.5 and $15 \mathrm{~h}$ post-hCG) being easier to induce than older oocytes (17 and $19 \mathrm{~h}$ ). The older oocytes were difficult to induce to cleave, and a longer duration of treatment with 6-DMAP may cause the accumulation of excessive abnormalities.

We found that 6-DMAP treatments alone had limited efficacy in inducing oocyte cleavage, with a maximum cleavage rate of $47.12 \%$. Consistent with previous studies, oocyte activation rate was low when 6-DMAP was used alone without any initiating stimulus [28,29]. The percentage of cleaved porcine oocytes and the rate of blastocyst formation [12] was higher in the ethanol + cycloheximide + cytochalasin B + 6-DMAP treatment (66.4\%) than in other separate treatments (24.9\%-57.6\%). Ferret oocytes cleaved at a rate of $85.8 \%$ when treated with combined electrical and chemical (cycloheximide and 6-DMAP) stimulations [13]. We found that chemical stimulation (6-DMAP, $2 \mathrm{~h}$ ) combined with electrical stimulation $(300 \mathrm{~V} / \mathrm{mm}, 10 \mu \mathrm{s})$ achieved cleavage rates of $96.49 \%$, higher than the rate stimulated by either treatment alone. We furthermore found that oocytes of different ages showed different tolerance levels to treatments, and higher voltage often caused lysis in younger oocytes. Therefore, lower pulse electrical stimulation combined with 6-DMAP treatment may be the best option in treating hamster oocytes of every age.

We conclude that the cleavage of golden hamster oocytes exhibits a strength-dependent increase when treated with electrical pulses from 10 to $500 \mathrm{~V} / \mathrm{mm}$. We further found that 6-DMAP can stimulate the oocyte cleavage, but the cleavage percentages are significantly lower than those stimulated under high-pulse electrical treatment. A combined treatment is superior to a 6-DMAP only treatment, and is nearly identical to the responses achieved by the high-pulse stimulus. These results define the optimal conditions for oocyte activation, and should facilitate cloning attempts of the golden hamster, furthering the system as an animal model for human disease.

Acknowledgments: This work was supported by the National Natural Science Foundation of China (No. 30671510) and Jinlin University Research Starting Fund of China.

Author Contributions: Lingyan Wang and Ziyi Li conceived and designed the experiments; Lingyan Wang and Han Jiang performed the experiments; Lingyan Wang analyzed the data; Ziyi Li contributed reagents/materials/analysis tools; Lingyan Wang and Ziyi Li wrote the paper.

Conflicts of Interest: The authors declare no conflict of interest. 


\section{References}

1. Wang, L.; Jiang, H.; Su, L.; Tang, B.; Li, D.; Li, Z. Effects of colchicine or demecolcine on cytoplasmic protrusions and assisted enucleation of golden hamster oocytes. Cell Biol. Int. 2009, 33, 1274-1279. [CrossRef] [PubMed]

2. Wang, L.; Li, D.; Li, Z. Changes in the reciprocal position of the first polar body and oocyte chromosome set in golden hamsters. Biosci. Rep. 2009, 29, 315-320. [CrossRef] [PubMed]

3. Ware, C.B.; Barnes, F.L.; Maiki-Laurila, M.; First, N.L. Age dependence of bovine oocyte activation. Gamete Res. 1989, 22, 265-275. [CrossRef] [PubMed]

4. Marcus, G.J. Activation of cumulus-free mouse oocytes. Mol. Reprod. Dev. 1990, 26, 159-162. [CrossRef] [PubMed]

5. Lan, G.C.; Ma, S.F.; Wang, Z.Y.; Luo, M.J.; Chang, Z.L.; Tan, J.H. Effects of post-treatment with 6-dimethylaminopurine (6-DMAP) on ethanol activation of mouse oocytes at different ages. J. Exp. Zool. A Comp. Exp. Biol. 2004, 301, 837-843. [CrossRef] [PubMed]

6. Presicce, G.A.; Yang, X. Parthenogenetic development of bovine oocytes matured in vitro for $24 \mathrm{~h}$ and activated by ethanol and cycloheximide. Mol. Reprod. Dev. 1994, 38, 380-385. [CrossRef] [PubMed]

7. Bodart, J.F.; Bechard, D.; Bertout, M.; Gannon, J.; Rousseau, A.; Vilain, J.P.; Flament, S. Activation of xenopus eggs by the kinase inhibitor 6-DMAP suggests a differential regulation of cyclin B and p39mos proteolysis. Exp. Cell Res. 1999, 253, 413-421. [CrossRef] [PubMed]

8. Escriba, M.J.; Garcia-Ximenez, F. Use of a variable electrical pulsing sequence in rabbit oocyte activation. Reprod. Nutr. Dev. 2000, 40, 261-269. [CrossRef] [PubMed]

9. Jiang, H.; Wang, C.; Guan, J.; Wang, L.; Li, Z. Changes of spontaneous parthenogenetic activation and development potential of golden hamster oocytes during the aging process. Acta Histochem. 2015, 117, 104-110. [CrossRef] [PubMed]

10. Sun, X.S.; Yue, K.Z.; Zhou, J.B.; Chen, Q.X.; Tan, J.H. In vitro spontaneous parthenogenetic activation of golden hamster oocytes. Theriogenology 2002, 57, 845-851. [CrossRef]

11. Gwatkin, R.B.; Williams, D.T.; Hartmann, J.F.; Kniazuk, M. The zona reaction of hamster and mouse eggs: Production in vitro by a trypsin-like protease from cortical granules. J. Reprod. Fertil. 1973, 32, 259-265. [CrossRef] [PubMed]

12. Yi, Y.J.; Park, C.S. Parthenogenetic development of porcine oocytes treated by ethanol, cycloheximide, cytochalasin B and 6-dimethylaminopurine. Anim. Reprod. Sci. 2005, 86, 297-304. [CrossRef] [PubMed]

13. Li, Z.; Jiang, Q.; Rezaei Sabet, M.; Zhang, Y.; Ritchie, T.C.; Engelhardt, J.F. Conditions for in vitro maturation and artificial activation of ferret oocytes. Biol. Reprod. 2002, 66, 1380-1386. [CrossRef] [PubMed]

14. Grupen, C.G.; Mau, J.C.; McIlfatrick, S.M.; Maddocks, S.; Nottle, M.B. Effect of 6-dimethylaminopurine on electrically activated in vitro matured porcine oocytes. Mol. Reprod. Dev. 2002, 62, 387-396. [CrossRef] [PubMed]

15. Nagy, A.; Gertsenstein, M.; Vintersten, K.; Behringer, R. Manipulating the Mouse Embryo: A Laboratory Manual, 3rd ed.; Cold Spring Harbor Laboratory Press: Cold Spring Harbor, NY, USA, 2003.

16. Yamauchi, Y.; Yanagimachi, R.; Horiuchi, T. Full-term development of golden hamster oocytes following intracytoplasmic sperm head injection. Biol. Reprod. 2002, 67, 534-539. [CrossRef] [PubMed]

17. Zimmermann, U.; Vienken, J. Electric field-induced cell-to-cell fusion. J. Membr. Biol. 1982, 67, $165-182$. [CrossRef] [PubMed]

18. Swann, K.; Ozil, J.P. Dynamics of the calcium signal that triggers mammalian egg activation. Int. Rev. Cytol. 1994, 152, 183-222. [PubMed]

19. Cheng, W.M.; Sun, X.L.; An, L.; Zhu, S.E.; Li, X.H.; Li, Y.; Tian, J.H. Effect of different parthenogenetic activation methods on the developmental competence of in vitro matured porcine oocytes. Anim. Biotechnol. 2007, 18, 131-141. [CrossRef] [PubMed]

20. Meo, S.C.; Yamazaki, W.; Ferreira, C.R.; Perecin, F.; Saraiva, N.Z.; Leal, C.L.; Garcia, J.M. Parthenogenetic activation of bovine oocytes using single and combined strontium, ionomycin and 6-dimethylaminopurine treatments. Zygote 2007, 15, 295-306. [CrossRef] [PubMed]

21. Wani, N.A. Chemical activation of in vitro matured dromedary camel (Camelus dromedarius) oocytes: Optimization of protocols. Theriogenology 2008, 69, 591-602. [CrossRef] [PubMed] 
22. Ogura, A.; Yanagimachi, R. Round spermatid nuclei injected into hamster oocytes from pronuclei and participate in syngamy. Biol. Reprod. 1993, 48, 219-225. [CrossRef] [PubMed]

23. Nagai, T. Parthenogenetic activation of cattle follicular oocytes in vitro with ethanol. Gamete Res. 1987, 16, 243-249. [CrossRef] [PubMed]

24. Hagen, D.R.; Prather, R.S.; First, N.L. Response of porcine oocytes to electrical and chemical activation during maturation in vitro. Mol. Reprod. Dev. 1991, 28, 70-73. [CrossRef] [PubMed]

25. Yanagimachi, R.; Chang, M.C. Fertilizable life of golden hamster ova and their morphological changes at the time of losing fertilizability. J. Exp. Zool. 1961, 148, 185-203. [CrossRef] [PubMed]

26. Moses, R.M.; Kline, D.; Masui, Y. Maintenance of metaphase in colcemid-treated mouse eggs by distinct calcium- and 6-dimethylaminopurine (6-DMAP)-sensitive mechanisms. Dev. Biol. 1995, 167, 329-337. [CrossRef] [PubMed]

27. Ledda, S.; Loi, P.; Bogliolo, L.; Moor, R.M.; Fulka, J., Jr. The effect of 6-dimethylaminopurine (6-DMAP) on DNA synthesis in activated mammalian oocytes. Zygote 1996, 4, 7-9. [CrossRef] [PubMed]

28. Liu, H.L.; Fan, B.Q.; Wang, H.H.; Cheng, Y.F.; Wang, G.J. [effect of 6-dimethylaminopurine on the resumption of meiosis and parthenogenetic activation in mouse oocytes]. Shi Yan Sheng Wu Xue Bao 1997, 30, 403-406. [PubMed]

29. Moses, R.M.; Masui, Y. Enhancement of mouse egg activation by the kinase inhibitor, 6-dimethylaminopurine (6-DMAP). J. Exp. Zool. 1994, 270, 211-218. [CrossRef] [PubMed]

(C) 2016 by the authors; licensee MDPI, Basel, Switzerland. This article is an open access article distributed under the terms and conditions of the Creative Commons Attribution (CC-BY) license (http:/ / creativecommons.org/licenses/by/4.0/). 